\title{
Chronic Stress and Its Association with Psychological, Behavioral and Physiological Variables of Mexican College Students
}

\author{
Elizabeth Pozos-Radillo*, Lourdes Preciado-Serrano, Ana Plascencia-Campos, \\ Katya Rayas-Servín \\ University Center for Health Sciences, University of Guadalajara, Guadalajara, Mexico \\ Email: *litaemx@yahoo.com.mx
}

Received 28 October 2015; accepted 14 December 2015; published 17 December 2015

Copyright (C) 2015 by authors and Scientific Research Publishing Inc.

This work is licensed under the Creative Commons Attribution International License (CC BY).

http://creativecommons.org/licenses/by/4.0/

c) (7) Open Access

\begin{abstract}
Chronic Stress in an academic environment is considered to be the physiological, emotional, cognitive and behavioral reaction to scholastic events. The objective of this study was to identify chronic stress and its association with psychological, behavioral and physiological variables of Mexican students at a public university. A representative random sample of 527 students in 2012 was assessed. The Stress Symptoms Inventory and the Rossi classification were used and a multiple regression analysis was carried out. Results showed that $35.3 \%$ of students displayed high levels of chronic stress; $44.8 \%$ medium levels and $19.9 \%$ low levels, and the variables of working, digestion problems, nail-biting, feeling depressed, isolation from others, are predictors of chronic stress. Early detection of the variables associated with chronic stress in students would facilitate the implementation of educational programs aimed at developing students' ability to cope with stressful situations.
\end{abstract}

\section{Keywords}

Stress, Students, Psychophysiological Disorders, Behavioral Symptoms, Universities

\section{Introduction}

Chronic stress is a physical, psychological and behavioral response stemming from a lack of control over situations perceived as threatening. Students often experience stress, which may lead to negative repercussions to their health as well as their academic performance. Its origin may be associated with different causes threatening

*Corresponding author.

How to cite this paper: Pozos-Radillo, E., Preciado-Serrano, L., Plascencia-Campos, A., \& Rayas-Servín, K. (2015). Chronic Stress and Its Association with Psychological, Behavioral and Physiological Variables of Mexican College Students. Advances in Applied Sociology, 5, 299-305. http://dx.doi.org/10.4236/aasoci.2015.512029 
the adaptive balance by reducing their coping abilities. Therefore, students are a vulnerable group with regards to stress-related diseases (Park, Edmondson, \& Lee, 2012).

Chronic stress is currently considered a trigger of alterations to the emotional state, of difficulties in interpersonal relations or of physical health. Some of the manifestations are identified in physiological reactions (or physiological unrelated to organic diseases), psychological (cognitive or emotional) and behavioral (attitude or behavior towards society) considered non-adaptive (Berrio \& Mazo, 2011; Costarelli \& Patsai, 2012; Diaz 2010).

High chronic stress levels in students may give rise to violence, toxic substance addiction, demotivation, boredom, difficulties in relations with schoolmates and in some cases school drop-out among others. Byrd and McKinney (2012) mention that moderate stress is good for learning and for immune responses but on the other hand, high chronic stress levels weaken the organism due to the fact that cortisol levels rise and may create mental or physical health problems (Jayakumar \& Sulthan, 2013; Arzate, 2011).

Some studies also associate stress with life events and with school activities such as academic overload and work (Surujlal, Zyl, \& Nolan, 2013). Psychological manifestations that have been reported are dissatisfaction or anxiety, social isolation and sleep-related (Furutani, Tanaka, \& Agari, 2011; Gulewstsch, Enck, SchwilleKiuntke, Weimer, \& Schlarb, 2013; Palmer, 2013). Physiological manifestations are mobility problems, visceral sensitivity and gastrointestinal functions (e.g. Cobo-Cuenca, Rodriguez, Sanchez, Vivo, Carbonell, \& Castellanos, 2012; Gulewitsch et al., 2013; Jayakumar \& Sulthan, 2013; Park et al., 2012).

Public university students in Mexico face several obstacles in developing their professional education, one of which is linked to high poverty levels in Mexico (Arzate, 2011). Some of them have to work in addition to studying and complete their academic load in different schedules (morning and afternoon) besides professional practices outside their school schedules. This may create an overload of activities that entails high chronic stress levels.

This study is based on the transactional theory of the social cognitive approach that conceives psychological stress as a particular relation between students and their environment that is viewed as threatening or overwhelms their coping resources and can jeopardize their wellbeing and academic performance (Gonzalez \& Landero, 2008).

Therefore, the purpose of this study was to identify chronic stress and its association with psychological, behavioral and physiological variables in Mexican students at a public university.

\section{Method}

\subsection{Participants}

A cross-sectional analytical study was made during the 2012 school year of undergrad students majoring in physical culture and sports at a public university in Guadalajara, Mexico. A simple random sample was made of the recorded population (976) of which $63 \%$ were men and $37 \%$ women. The size was determined with an expected prevalence of 64.5\% (Marty, Lavin, Figueroa, Larrain de la C, \& Cruz, 2005) and a minimum acceptable frequency of 70\%, an accuracy level of 99\% (Lwanga \& Lameshow, 1991) requiring a sample size of 527 students who were interviewed individually. The college students were selected with the random number technique, proportionate according to gender and semester at college. The list of students enrolled in the 2012 schoolyear enabled a search of those chosen to answer the survey voluntarily and who gave their informed consent. The research protocol and the informed consent form were reviewed and approved with reference number IISO/CI/11/2012-2013 pursuant to the 2008 Declaration of Helsinki regarding the ethics of research with human beings.

\subsection{Instruments}

\section{Stress Symptoms Inventory (SSI)}

This inventory, created and validated by Lipp and Guevara (1994), contains a list of 41 Psychophysiological Symptoms characteristic of chronic stress, based on the three-phase model developed by Selye (alarm, resistance and exhaustion). Dominguez adapted it in Mexico in 1998 with a content validation that reports an internal Cronbach alpha consistency of .94, indicative of an acceptable degree of reliability. The classification into high, 
medium and low levels of chronic stress was based on the average and standard deviation (SD). A high level was considered to greater than two and three SD; the medium level was less than one SD, and a low level less than two and three SD (Pozos-Radillo, Torres, Aguilera, Acosta, \& Gonzalez, 2008).

A questionnaire was used to gather information about psychological, behavioral and physiological variables based on the classification established by Rossi (2001): physiological variables mean those implying a physical reaction (nail-biting, muscle tremors, headache, insomnia, chronic fatigue, digestion problems and drowsiness); psychological variables are those involving cognitive or emotional functions (restlessness, anxiety, mental block, feeling depressed, despair and memory problems); and behavioral variables are those having to do with the person's behavior (arguing, isolation from others, classroom absenteeism, eating more or less and listlessness towards performing academic work). To assess the participants, they were asked whether they had had any of these symptoms during the past six months. The questionnaire offered four multiple choices for an answer $(1=$ never to 2 = always).

The variables of gender, college semester, if they worked and age (in 5-year intervals) were also analyzed as predictive variables.

\subsection{Procedure}

The Pearson correlation analysis was applied as a perquisite for the multiple regression analysis, with chronic stress as the response variable and psychological, behavioral, physiological, age, college semester and work variables as the predictive variables, considering a model with a significance level of $p>.05$.

The analysis of variables is ordered in the equation in terms of the percentage of explained variance.

Then a hierarchical multiple regression analysis was applied to determine the predictive value of the physiological, psychological and behavioral variables with regard to chronic stress in which the Introducer method was used. An increased prediction value of the variable listed in fifth place was obtained with this procedure, once the effect of the fourth, third, second and first ones were controlled.

The data were tabulated and processed with the Statistical Package for Social Sciences (SPSS), Version 15 for Windows XP, under the university's license.

\section{Results and Findings}

527 students at a public university were interviewed: 311 (59\%) females and 216 (41\%) male. The age range was between 18 and 33 years old, the average age was 21.07 ( \pm 1.80 years), 243 (46\%) of them worked and academic levels ranged from first to eighth semester, as seen in Table 1.

The descriptive analysis of the physiological, psychological and behavioral variables showed that the most frequent ones were: the physiological variable, digestion problems with $56 \%$ (294); the psychological variable, restlessness with $39 \%$ (204), the behavioral variables, isolation from others with 66\% (348); their distribution is shown in Table 1.

Predictive value of SSI in association with physiological, psychological and behavioral variables as well as age, college semester and work.

The correlations of Stress Symptoms Inventory (SSI) scores with the variables of this study showed moderate to strong positive correlations (Pearson $r>.30$ ). The symptom with a strong correlation was isolation from others $(\mathrm{r}=.76 ; p<.01)$. The variables with a moderate correlation were: nail-biting $(\mathrm{r}=.36 ; p=<.01)$, working $(\mathrm{r}$ $=.51 ; p<.01)$, digestion problems $(\mathrm{r}=.52 ; p=<.01)$, and feeling depressed $(\mathrm{r}=.64 ; p=<.01)$ (Table 2$)$.

Variables showing a low or inverse correlation (Pearson $r<.30$ ) were not taken into consideration in this study. Those with a low correlation were: eating more or less; classroom absenteeism; drowsiness; arguing; restlessness; chronic fatigue; listlessness towards performing academic work; anxiety; despair; muscle tremors; memory problems; mental block and concentration problems. Those with an inverse correlation were: college semester; age; gender; insomnia and migraines.

The correlation coefficients obtained in the stepwise regression for chronic stress scored with the ISE of each of the variables: psychological, behavioral, physiological, gender, age, academic year and work, that met the prediction criteria and had significance value, revealed that working, digestion problems, isolation from others, nail-biting and feeling depressed were predictors of chronic stress $\left.\left(\mathrm{R}^{2}=.67\right) \mathrm{F}=14.9, p<.05\right)$.

The variable isolated from the others was the first one entered into the model and made up $20 \%$ of the SSI prediction with $\mathrm{F}=9.8(p<.01)$. Nevertheless, when the variables of working, digestion problems, nail-biting 
Table 1. Distribution of chronic stress according to psychological, behavioral, physiological, gender, age, college semester and work variables of students at a public university in Guadalajara, Mexico $2012 \mathrm{~N}=527$.

\begin{tabular}{|c|c|c|c|c|c|c|c|c|}
\hline \multirow{3}{*}{ LEVELS } & \multicolumn{8}{|c|}{ CHRONIC STRESS } \\
\hline & \multicolumn{2}{|c|}{ HIGH } & \multicolumn{2}{|c|}{ MEDIUM } & \multicolumn{2}{|c|}{ LOW } & \multicolumn{2}{|c|}{ TOTAL } \\
\hline & $\mathbf{F X}$ & $\%$ & $\mathbf{F X}$ & $\%$ & FX & $\%$ & $\mathbf{F X}$ & $\%$ \\
\hline \multicolumn{9}{|l|}{ PSYCHOLOGICAL } \\
\hline Restlessness & 78 & 5.1 & 88 & 16.7 & 38 & 7.2 & 204 & 38.7 \\
\hline Concentration Problems & 66 & 12.5 & 74 & 14.0 & 28 & 5.3 & 168 & 31.9 \\
\hline Mental block & 78 & 14.8 & 77 & 14.6 & 31 & 5.9 & 186 & 32.3 \\
\hline Feeling depressed & 84 & 15.9 & 76 & 14.4 & 32 & 6.1 & 192 & 36.4 \\
\hline Anxiety & 73 & 13.8 & 79 & 14.9 & 36 & 6.8 & 188 & 25.6 \\
\hline Despair & 64 & 12.1 & 79 & 14.9 & 25 & 4.7 & 168 & 31.9 \\
\hline Memory problems & 83 & 15.7 & 78 & 14.8 & 31 & 5.9 & 192 & 36.4 \\
\hline \multicolumn{9}{|l|}{ PHYSIOLOGICAL } \\
\hline Nail-biting & 101 & 19.2 & 94 & 17.8 & 49 & 9.3 & 244 & 46.3 \\
\hline Muscle tremors & 73 & 13.8 & 98 & 18.6 & 42 & 8.0 & 213 & 40.4 \\
\hline Migraines & 53 & 10.0 & 75 & 14.2 & 37 & 7.0 & 165 & 31.3 \\
\hline Insomnia & 90 & 17.1 & 94 & 17.8 & 60 & 11.4 & 244 & 46.3 \\
\hline Chronic fatigue & 89 & 16.9 & 99 & 18.8 & 28 & 5.3 & 216 & 41.4 \\
\hline Digestion problems & 118 & 22.4 & 117 & 22.2 & 59 & 11.2 & 294 & 55.8 \\
\hline Drowsiness & 58 & 11.0 & 69 & 13.1 & 25 & 4.7 & 152 & 28.8 \\
\hline \multicolumn{9}{|l|}{ BEHAVIORAL } \\
\hline Arguing & 71 & 13.5 & 87 & 16.5 & 30 & 5.7 & 188 & 35.7 \\
\hline Isolation from othe & 131 & 24.8 & 177 & 33.5 & 40 & 7.6 & 348 & 66.0 \\
\hline rs Classroom absenteeism & 82 & 15.5 & 94 & 17.8 & 26 & 4.9 & 202 & 38.3 \\
\hline Eating less or more & 25 & 4.7 & 32 & 6.1 & 7 & 1.4 & 64 & 12.1 \\
\hline Listlessness towards working & 80 & 15.2 & 86 & 16.3 & 43 & 8.1 & 209 & 39.6 \\
\hline \multicolumn{9}{|l|}{ GENDER } \\
\hline Female & 121 & 22.9 & 129 & 24.5 & 61 & 11.6 & 311 & 59.0 \\
\hline Male & 65 & 12.3 & 107 & 20.3 & 44 & 8.3 & 216 & 41.0 \\
\hline \multicolumn{9}{|l|}{ AGE } \\
\hline $18-23$ & 80 & 12.2 & 93 & 17.6 & 39 & 7.4 & 212 & 40.2 \\
\hline $21-23$ & 85 & 16.1 & 127 & 24.1 & 58 & 11.0 & 270 & 51.2 \\
\hline $24-29$ & 21 & 4.0 & 16 & 3.0 & 6 & 1.1 & 43 & 8.1 \\
\hline $30 y^{+}$ & 0 & 0.0 & 0 & 0.0 & 2 & 0.4 & 2 & 0.4 \\
\hline \multicolumn{9}{|l|}{ COLLEGE SEMESTER } \\
\hline First & 4 & 0.7 & 6 & 1.1 & 4 & 0.7 & 14 & 2.6 \\
\hline Second & 15 & 2.8 & 17 & 3.2 & 4 & 0.7 & 36 & 6.8 \\
\hline Third & 37 & 7.0 & 45 & 8.5 & 22 & 4.2 & 104 & 19.7 \\
\hline Fourth & 33 & 6.3 & 33 & 6.3 & 19 & 3.6 & 85 & 16.1 \\
\hline Fifth & 32 & 6.1 & 40 & 7.6 & 10 & 1.9 & 82 & 15.5 \\
\hline Sixth & 21 & 4.0 & 34 & 6.4 & 13 & 2.5 & 68 & 12.9 \\
\hline Seventh & 18 & 3.4 & 30 & 5.7 & 22 & 4.2 & 70 & 13.3 \\
\hline Eighth & 26 & 4.9 & 31 & 5.9 & 11 & 2.1 & 68 & 12.9 \\
\hline \multicolumn{9}{|l|}{ WORK } \\
\hline Yes & 115 & 21.8 & 121 & 23.0 & 48 & 9.1 & 284 & 53.9 \\
\hline No & 71 & 13.5 & 115 & 21.8 & 57 & 10.8 & 243 & 46.1 \\
\hline
\end{tabular}

Note: SSI questionnaire $=$ chronic stress. 
Table 2. Correlation matrix of scores obtained by college students for chronic stress and psychological, behavioral, physiological and work variables of students at a public university in Guadalajara, Mexico 2012.

\begin{tabular}{|c|c|c|c|c|c|c|}
\hline & SSI & Digestion problems & Feeling depressed & Working & Isolation from others & Nail-biting \\
\hline SSI & --- & & & & & \\
\hline Digestion problems & $0.52^{*}$ & --- & & & & \\
\hline Feeling depressed & $0.64^{* *}$ & $0.30^{* *}$ & -- & & & \\
\hline Working & $0.51^{* *}$ & $0.70^{* *}$ & $0.39^{* *}$ & --- & & \\
\hline Isolation from others & $0.76^{* *}$ & $0.45^{* *}$ & $0.06^{* *}$ & $0.38^{* *}$ & --- & \\
\hline Nail-biting & $0.36^{* *}$ & $0.52^{* *}$ & $0.65^{* *}$ & $0.85^{* *}$ & $0.58^{* *}$ & --- \\
\hline
\end{tabular}

Note: SSI $=$ chronic stress ${ }^{*} p<.05 ;{ }^{* *} p<.01$.

and feeling depressed were introduced, the predictive model remained at $67 \%$ of the variance. The regressive equation was composed as follows: SSI $=.24$ (working) +.31 (digestion problems) +.48 (isolation from others) +.68 (nail-biting) +.83 (feeling depressed) +.088 . The other variables with low or inverse correlations were excluded from the model, significantly increasing the explained ISE percentage (Table 3).

Further to these analyses, different contrasts were made in connection with the assumptions of independence, normality and homoscedasticity. We should point out in this regard that the data does not show multicollinearity between the predictive variables, as was expected. The average statistical values of "Tolerance" for the psychological, behavioral, physiological and work variables was .97 with no value below .94. The proximity of these values to the maximum value (range of 0 - 1) indicated the independence of the contributions of predictive variables above the chronic stress values, thereby indicating that the residual variance was constant and residuals were distributed normally. The average VIF value $=1.02$ with no value below 1.00 showed that there is no problem with multicollinearity.

\section{Discussion}

The study showed the existence of a meaningful association between some psychological, behavioral, physiological, and work variables and chronic stress. Associated physiological variables were: digestive problems and nail-biting. Behavioral variables were only associated with isolation from others while the only association found with psychological variables was feeling depressed. A positive correlation occurred, indicating a dependence between these variables and chronic stress; i.e., when one of them increases, the other one also increases at a constant proportion. We should mention that this is the first predictive report identifying the existence of an association between chronic stress and psychological, behavioral and physiological symptoms in college students at a public university in Guadalajara, Mexico.

The resulting regression model of this investigation contributes to the transactional theory of the social cognitive approach that underscores the interaction of stress variables based on cognitive processes that develop around a stressful situation as the internal representation of particular and problematic assessments between students and their academic environment.

Previous studies have shown that chronic stress is present in college students associated with anxiety, academic overload and dissatisfaction (Furutani et al., 2011; Gulewitsch et al., 2013 and Palmer, 2013) as well as with social isolation, insomnia, nail-biting and gastrointestinal problems (e.g. Chen et al., 2013; Cobo-Cuenca et al., 2012; Jayakumar \& Sulthan, 2013; Mounsey, Vandehey, \& Diekhoff, 2013; Park et al., 2012). The results of these investigations agree with those presented here but differ in "feeling depressed" and "working”. These differences may be due to the variation of study designs, the variables and due to the different situations they are associated with, such as anxiety, heart rate, academic stress, coping, beliefs and students' inclination to have low academic performance, as well as the different curricula taught at the educational institution where students enrolled (Mounsey et al., 2013; Pettit \& DeBarr, 2011; Reang \& Bhattacharjya, 2013; Surujlal et al., 2013).

With regards to the variable "working while studying”, some studies mention that while working may be positive for some college students, for others it may have negative effect due to the double load (Ablanedo-Rosas, Blevins, Gao, Teng, \& White, 2011; Reang \& Bhattacharjya, 2013). 
Table 3. Hierarchical multiple regression analysis of each of the psychological, behavioral, physiological, and work variables of students at a public university in Guadalajara, Mexico 2012.

\begin{tabular}{|c|c|c|c|c|c|c|}
\hline REGRESSION MODEL & Beta & ET & $(p)$ & $\mathrm{R}^{2}$ & $\mathrm{~F}$ & $\mathrm{n}$ \\
\hline Constant & 0.08 & & & 0.67 & 14.9 & \\
\hline Working & 0.24 & 1.79 & $<.01$ & & & 284 \\
\hline \multicolumn{7}{|c|}{ PHYSIOLOGICAL VARIABLES } \\
\hline Digestion problems & 0.31 & 1.19 & $<.01$ & & & 294 \\
\hline \multicolumn{7}{|c|}{ PSYCHOLOGICAL VARIABLES } \\
\hline Isolation from others & 0.48 & 1.90 & $<.01$ & & & 370 \\
\hline \multicolumn{7}{|l|}{ BEHAVIORAL VARIABLES } \\
\hline Nail-biting & 0.68 & 2.19 & $<.05$ & & & 244 \\
\hline Feeling depressed & 0.83 & 3.20 & $<.05$ & & & 192 \\
\hline
\end{tabular}

Note: SSI questionnaire $=$ chronic stress. ${ }^{*} p<.05 ;{ }^{* *} p<.01$.

Ablanedo-Rosas et al. (2011) found that some students who work are under pressure and have financial problems, which may cause low academic performance. Another negative aspect related to work and school schedules is that students have to make adjustments to meet both demands. This could create problems at work and/ or at school, leading to increased anxiety or a state of depression (Chen et al., 2013; McGowan \& Kagee, 2013).

Our study also detected that there is more presence of medium chronic stress levels, a situation that should be considered alarming because SSI is based on manifest symptoms and a lack of timely intervention to reduce them to low levels could evolve into high chronic stress levels at any time.

It also observed that despite the fact that the gender variable failed to show a meaningful association according to the multiple regression analysis, women displayed higher levels of chronic stress as well as more psychological, behavioral and physiological symptoms than men. Therefore close attention must be paid to this population. Other studies have found that the female gender is at greater risk for stress (e.g., Pozos-Radillo et al., 2008; Reang \& Bhattacharjya, 2013). The difference between the results of some authors and those of this work lies in the fact that the association was more specific regarding psychological, behavioral and physiological variables as well as chronic stress.

Among the strengths of this study are the sample size, which is large and representative. $54 \%$ of the total population of students studying at a public university towards a bachelor's degree in one area were interviewed; this is a greater inclusion of students in comparison with other studies dealing with stress (Reang \& Bhattacharjya, 2013; Gulewitsch et al., 2013; Cobo-Cuenca et al., 2012). Furthermore, it is important to mention the limitations of this study, mainly the existence of other factors that might have influenced chronic stress at the time the questionnaires were applied such as social, economic and cultural characteristics that were not considered in this study.

\section{Conclusion}

College students, with chronic stress and who work tend to bite their nails and show isolation from others, have digestion problems and feel depressed unlike students without chronic stress and who do not work.

When the different psychological, behavioral and physiological variables interact among themselves, they create a vicious circle in that thoughts, emotions and behavior can become increasingly more negative and less adaptive. This may trigger negative emotional states that result in inadequate behavior, and said behavior at the same time may have a negative influence on the academic environment, thus creating more stress. So an accurate and timely identification of stressors may help understand the stress. We further recommend implementing educational programs aimed at preventing stress and its negative effects and that develop students' ability to cope with stressful situations; we further recommend including academic performance and social, economic and cultural characteristics in future studies. 


\section{References}

Ablanedo-Rosas, J. H., Blevins, C., Gao, H., Teng, W.-Y., \& White, J. (2011). The Impact of Occupational Stress on Academic and Administrative Staff, an Empirical Case Analysis. Journal of Higher Education Policy and Management, 33, 553-564. http://dx.doi.org/10.1080/1360080X.2011.605255

Arzate, S. J. (2011). Analytical Evaluation of Compensatory Educational Policies in Mexico: The Case of Programs in the Fight against Poverty, 1988-2011. Revista Mexicana de Investigación Educativa, 16, 1055-1085.

Berrio, G. N., \& Mazo, Z. R. (2011). Academic Stress. Revista de Psicología de la Universidad de Antioquia, 3, 65-82.

Byrd, D. R., \& McKinney, K. J. (2012). Individual, Interpersonal, and Institutional Level Factors Associated with the Mental Health of College Students. Journal of American College Health, 60, 185-193. http://dx.doi.org/10.1080/07448481.2011.584334

Chen, L., Wang, L., Hui, X., Xian, X., Xue, Z., Jie, Y. et al. (2013). Depression among Chinese University Students: Prevalence and Socio-Demographic Correlates. PLOS ONE, 8, 1-6.

Cobo-Cuenca, A. I., Rodríguez, A. C., Sánchez, D. A., Vivo, O. I., Carbonell, G. R., \& Castellanos, R. R. (2012). Perceived Stressors and Anxiety of Nursing Students in Their First Clinical Practice Period. Ansiedad y Estrés, 18, 91-101.

Costarelli, V., \& Patsai, A. (2012). Academic Examination Stress Increases Disordered Eating Symptomatology in Female University Students. Eating and Weight Disorders, 17, 64-69. http://dx.doi.org/10.1007/BF03325343

Diaz, M. Y. (2010). Academic Stress and Coping in Medical Students. Humanidades Médicas, 10, 2-10.

Furutani, M., Tanaka, H., \& Agari, I. (2011). Anxiety and Heart Rate Variability before Sleep Indicate Chronic Stress in Students. Perceptual and Motor Skills, 112, 138-150. http://dx.doi.org/10.2466/09.13.PMS.112.1.138-150

Gonzalez, R. M., \& Landero, H. R. (2008). Confirmation of a Descriptive Model of Stress and Psychosomatic Symptoms Using Structural Equations. Revista Panamericana de Salud Pública, 23, 7-18.

Gulewitsch, M., Enck, P., Schwille-Kiuntke, J., Weimer, K., \& Schlarb, A. (2013). Mental Strain and Chronic Stress among University Students with Symptoms of Irritable Bowel Syndrome. Gastroenterology Research and Practice, 25, 12231229. http://dx.doi.org/10.1155/2013/206574

Jayakumar, D. S., \& Sulthan, A. (2013). Stress Symptoms: Structural Equation Modelling. Journal of Indian Management, 13, 95-109.

Lipp, E. N., \& Guevara, J. H. (1994). Empirical Validation of the Inventory of Stress Symptoms (SSI). Estudios de Psicología, 11, 43-49.

Lwanga, K., \& Lameshow, S. (1991). Sample Size Determination in Health Studies. Geneva, Nueva York: World Health Organization. http://whqlibdoc.who.int/publications/9241544058 (p1-p22).pdf

Marty, M., Lavín, M., Figueroa, M., Larraín de la, D., \& Cruz, C. (2005). Prevalence of Stress in Health Sciences Students at Los Andes University and Its Relation to Infectious Diseases. Revista chilena de neuro-psiquiatria, 43, 25-32.

McGowan, T., \& Kagee, A. (2013). Exposure to Traumatic Events and Symptoms of Post-Traumatic Stress among South African University Students. South African Journal of Psychology, 43, 327-339. http://dx.doi.org/10.1177/0081246313493375

Mounsey, R., Vandehey, M., \& Diekhoff, G. (2013). Working and Non-Working University Students: Anxiety, Depression, and Grade Point Average. College Student Journal, 47, 379-389.

Palmer, L. (2013). The Relationship between Stress, Fatigue, and Cognitive Functioning. Collegue Student Journal, 47, 312325.

Park, C., Edmondson, D., \& Lee, J. (2012). Development of Self-Regulation Abilities as Predictors of Psychological Adjustment across the First Year of College. Journal of Adult Developmen, 19, 40-49. http://dx.doi.org/10.1007/s10804-011-9133-z

Pettit, L., \& DeBarr, A. (2011). Perceived Stress, Energy Drink Consumption, and Academic Performance among College Students. Journal of American College Health, 59, 335-341. http://dx.doi.org/10.1080/07448481.2010.510163

Pozos-Radillo, B. E., Torres, T., Aguilera, M., Acosta, M., \& González, G. (2008). Stress-Associated Factors in Mexican Dentists. Brazilian Oral Research, 22, 223-228. http://dx.doi.org/10.1590/S1806-83242008000300006

Reang, T., \& Bhattacharjya, H. (2013). A Study to Assess the Emotional Disorders with Special Reference to Stress of Medical Students of Agartala Government Medical College and Govinda Ballabh Pant Hospital. Indian Journal of Community Medicine, 38, 207-211. http://dx.doi.org/10.4103/0970-0218.120154

Rossi, R. (2001). To Overcome Stress. Tips the Psychologist. Barcelona: De Vecchi.

Surujlal, J., Van, Y., \& Nolan, V. (2013). Perceived Stress and Coping Skills of University Student-Athletes and the Relation Ship with Life Satisfaction. African Journal for Physical, Health Education, Recreation and Dance, 19, 1047-1059. 